\title{
Carboxyhemoglobin and Methemoglobin as Markers of Postoperative Pulmonary Complications
}

\author{
Aleksandra Gavrilovska-Brzanov ${ }^{{ }^{*}}$, Maja Slaninka Miceska ${ }^{2}$, Mirjana Shosholcheva ${ }^{3}$, Biljana Kuzmanovska ${ }^{1}$ \\ Andrijan Kartalov ${ }^{1}$, MajaMojsova-Mijovska ${ }^{1}$, Marija Jovanovski-Srceva ${ }^{1}$, Risto Simeonov ${ }^{4}$, Nikola Brzanov ${ }^{1}$ \\ ${ }^{1}$ University Clinic for Traumatology, Orthopedic disease, Anesthesiology, Reanimation and Intensive Care Medicine and Emergency department, Faculty of \\ Medicine, University "Ss. Cyril and Methodius", Skopje, R. Macedonia \\ ${ }^{2}$ Department of Preclinical and Clinical Pharmacology and Toxicology, Faculty of Medicine, University "Ss. Cyril and Methodius", Skopje, R. Macedonia \\ ${ }^{3}$ University Clinic for General Surgery "St. NaumOhridski" Faculty of Medicine, University "Ss. Cyril and Methodius", Skopje, R. Macedonia \\ ${ }^{4}$ University Clinic for Pediatric Surgery, Faculty of Medicine, University "Ss. Cyril and Methodius”, Skopje, R. Macedonia
}

*Corresponding author: Aleksandra Gavrilovska-Brzanov, University Clinic for Traumatology, Orthopedic disease, Anesthesiology, Reanimation and Intensive Care Medicine and Emergency department, Faculty of Medicine, University "Ss. Cyril and Methodius", Bul. Jane Sandanski 84/3-14 Skopje Macedonia, Tel: 0038971240 701; E-mail: gavrilovska.aleksandra@gmail.com

\begin{abstract}
:
Introduction: The inhalation of tobacco smoke can substantially raise the level of carboxyhemoglobin in the blood. Determination of the level of carboxyhemoglobin and methemoglobin can identify patients with increased risk for development of postoperative pulmonary complications.

Material and Methods: Thirty patients scheduled for elective urologic surgery under general endotracheal anesthesia were allocated in two groups $(\mathrm{n}=15 \mathrm{each})$. The study group comprised patients who were smoking cigarettes or tobacco pipe, while the control group included non-smokers. In both group's carboxyhemoglobin and methemoglobin levels were determined preoperatively, after preoxygenation, and one hour after completing the anesthesia. Postoperative pulmonary complications were assessed and recorded during the period of hospitalization.

Results: The average values of carboxyhemoglobin between the two groups were statistically significantly different. Postoperative carboxyhemoglobin was higher in smokers compared to control non-smokers group $(p=0.000)$. On the other hand, methemoglobin was higher in the control non-smokers group compared to smokers, but without statistical significance $(\mathrm{p}=0.88)$. Regarding postoperative pulmonary complications, $13.3 \%$ of the patients in the control non-smokers group and $26.6 \%$ of the patients in smokers group had pulmonary complications.

Conclusion: In our sample there was a difference between the incidence rates of postoperative pulmonary complications; however, we cannot confirm the hypothesis that carboxyhemoglobin and methemoglobin can serve as predictors for postoperative pulmonary complications.
\end{abstract}

Keywords: Methemoglobin; Carboxyhemoglobin; Postoperative pulmonary complications; Urologic surgery

\section{Introduction}

Postoperative Pulmonary Complications (PPC) is particularly relevant to the anesthetic community because ventilation is under the control of the anesthetist during the intraoperative period. Despite recent remarkable advances in anesthesia and surgical care PPC still remain significant problem in clinical practice ${ }^{[1]}$. PPC are associated with increased length of hospital stay, mortality after surgery and hospital costs ${ }^{[2]}$. It is clinically important to identify patients at high risk of postoperative respiratory complications because early prediction of risk allows for preoperative triage and better healthcare resource allocation ${ }^{[3]}$. Cigarette smoke has been identified with wide-ranging effects on the respiratory system ${ }^{[4]}$. Cigarette smoke also alters the transport and delivery of oxygen to the tissues. Tobacco smoking generally leads to a decrease in mucociliary transport. The irritants from tobacco increase mucus secretion, and the mucus becomes hyperviscous. Furthermore tobacco induces ciliostasis. All of the above mentioned lead to diminished tracheobronchial clearance ${ }^{[5]}$. Cigarette smoke can lead to small airway narrowing and collapsing, which predisposes the lung to infections, coughing, pulmonary complications and prolonged mechanical ventilation ${ }^{[6]}$.
Received date: March 13, 2018

Accepted date: May 15, 2018

Published date: May 21, 2018

Citation: Gavrilovska-Brzanov, A., et al. Carboxyhemoglobin and Methemoglobin as Markers of Postoperative Pulmonary Complications. (2018) J Anesth Surg 5(1): 61- 67.

Copy Rights: (C) 2018 GavrilovskaBrzanov, A. This is an Open access article distributed under the terms of Creative Commons Attribution 4.0 International License. 
Citation: Gavrilovska-Brzanov, A., et al. Carboxyhemoglobin and Methemoglobin as Markers of Postoperative Pulmonary Complications. (2018) J Anesth Surg 5(1): $61-67$.

Previous study shows that the component of smoke that has a major effect on the respiratory system is carbon monoxide leading to increased level of carboxyhemoglobin $(\mathrm{COHb})$ [7]. On the other hand, methemoglobin (MetHb) presents oxidative deoxy form of hemoglobin which cannot binds oxygen ${ }^{[8]}$. Increased fractions of $\mathrm{COHb}$ and $\mathrm{MetHb}$ are dangerous for two reasons: $\mathrm{COHb}$ and $\mathrm{MetHb}$ inhibit $\mathrm{O}_{2}$ transport by blocking heme iron-binding sites; and when one or more iron atoms have bound carbon monoxide or been oxidized, the hemoglobin conformation is changed so that the oxygen affinity of the remaining heme groups is increased, thus shifting the oxygen $\left(\mathrm{O}_{2}\right)$ dissociative curve to the left, and decreasing oxygen delivery to tissues. These forms of hemoglobin can only be measured by a multi wavelength spectrophotometer such as a $\mathrm{CO}$ - oximeter through arterial blood sample ${ }^{[9]}$. At present there is still no evidence of a simple, useful and widely applicative scoring for prediction of postoperative pulmonary complications ${ }^{[1,2]}$. We hypothesized that the values of $\mathrm{COHb}$ and MetHb correlate with PPC and can serve as prognostic markers for developing PPC.

\section{Materials and Methods}

The study adhered to the principles of the Declaration of Helsinki for medical research involving human subjects and was approved by the Ethics Committee at the Medical Faculty (no: 03-4407/8) and by the Institutional Review Boards of the University Clinic for Anesthesia, Reanimation and Intensive Care "Mother Theresa" in Skopje. We conducted a single center, prospective, observational study. We enrolled all consecutive adult patients aged 18 and 60 years, scheduled for elective urologic surgery under general endotracheal anesthesia, without any history of respiratory disease, physiological score for preoperative assessment of health - ASA (American Society of Anesthesiologists) I and II. The patients were randomly assigned into two groups. The patients in the study group (group I, $\mathrm{n}=$ 15 ) were smokers, and in the control group (group II, $n=15$ ) patients were never-smokers ${ }^{[10]}$. We excluded all transplant patients, patients having surgery under local or regional anesthesia, pregnant patients, patients brought in operating theater intubated, patients with any history of respiratory disease ${ }^{[1,11,12]}$.

\section{Study protocol}

On admission every patients underwent a standard clinical preoperative protocol, which include clinical examination and evaluation for existence of any respiratory symptoms or disease $^{[13]}$.

On the day of surgery, 90 minutes before intervention patients were premedicated with oral Diazepam $5 \mathrm{mg}$. In the operating theatre all patients were continuously hemodynamically monitored. After performing standard Allen test for circulation $^{[14]}$ intra-arterial line was placed in the radial artery. The standardized intravenous anesthesia protocol was commenced for both groups. The induction was accomplished after preoxygenation with $100 \% \mathrm{O}_{2} / 6 \mathrm{~L} / \mathrm{min}$, for 3 minutes with midazolam 1-2 $\mathrm{mg}$, fentanil (2-10 $\mu \mathrm{g} / \mathrm{kg})$ and propofol $(2 \mathrm{mg} / \mathrm{kg})$. The intubation was facilitated with rokuroniumbromid $0.5 \mathrm{mg} / \mathrm{kg}$. The anesthesia was maintained with fentanyl $1-2 \mathrm{mcg} / \mathrm{kg}$, continuous infusion of propofol $0.1-0.2 \mathrm{mg} / \mathrm{kg} / \mathrm{min}$, and rocuronium bromide $0.3 \mathrm{mg} / \mathrm{kg}$. The patients were mechanically ventilated with inhaled fraction with a mixture of $\mathrm{O}_{2}(50 \%)$ and air $(50 \%)$, PEEP $5 \mathrm{~cm} \mathrm{H}_{2} \mathrm{O}, 6-8 \mathrm{ml} / \mathrm{kg}$ tidal volume $\left(\mathrm{V}_{\mathrm{T}}\right)$. Respiratory rate was adjusted according to the $\mathrm{ETCO}_{2} 35-45 \mathrm{mmHg}$.

In the end of surgery all patients were transferred to post-anesthesia care unit (PACU). In PACU they were placed on continuous heart rate and peripheral oxygen saturation monitoring. The length of stay in the PACU was recorded together with the appearance of any complications during the stay.

Postoperatively patients were followed for presence and appearance of any respiratory system signs and symptoms until the discharge from the hospital ${ }^{[11,15,16]}$.

\section{Measurements}

Arterial blood gas analysis was performed at three time points: $T_{0}$ - before surgery under respiration with room air; $T_{1}$ after pre-oxygenation, and $\mathrm{T}_{2}$ - one hour after surgery in PACU under respiration with room air or oxygen inhalation with or without endotracheal intubation. Levels of $\mathrm{COHb}$ and $\mathrm{MetHb}$ were determined from arterial blood sample. $\mathrm{COHb}$, MetHb, total $\mathrm{Hb}$, fractional oxyhemoglobin $\left(\mathrm{FO}_{2} \mathrm{Hb}\right)$ and partial pressure of carbon dioxide $\left(\mathrm{PCO}_{2} \mathrm{mmHg}\right)$ and oxygen $\left(\mathrm{PO}_{2} \mathrm{mmHg}\right)$ in arterial blood samples were analyzed and measured by blood gas analyzer (SIEMENS RAPID Point 500 Systems). COHb and $\mathrm{MetHb}$ were analyzed spectrophotometrically. To guarantee accuracy at least every 4 hours, the analyzer runs a zero calibration of the optical system against a colorless calibration fluid. Any other biochemical measurements and electrolyte levels were determined by standard laboratory methods.

Appearance of any postoperative respiratory complication were recorded and analyzed ${ }^{[11,15]}$ : new detection of respiratory wheezing treated with bronchodilators, persistent coughing $>15$ seconds, respiratory insufficiency, re-intubation, atelectasis, aspiration pneumonia, pneumothorax, pleural effusion, laryngospasm, bronchospasm, pneumonia, acute respiratory distress syndrome (ARDS), pulmonary embolism ${ }^{[15]}$. Secondary outcomes of interest were: the time of anesthesia and surgery, postoperative length of stay and in-hospital mortality, postoperative ICU admission.

\section{Statistical analysis}

The databases were created with the help of computer programs, the processing of which is made with the standard descriptive and analytical methods. The attributive and numerical data were analyzed using the odds relations, proportions or the measure of the central tendency and are reported as medians and ranges, and categorical variables are expressed as percentages. The statistical significance was tested with analysis of variance and difference. The significance is indicated when $\mathrm{p}<0.05$.

\section{Results}

According to the inclusion criteria the pilot study enrolled 30 patients in both groups who underwent elective urologic surgery. They were divided in two groups: smokers (group $\mathrm{I}, \mathrm{n}=15$ ), control non-smokers group (group II, $\mathrm{n}=15$ ). The baseline demographic characteristics were similar between both groups of patients with respect to sex, age, weight, height BMI and ASA.

(Figure 1) 


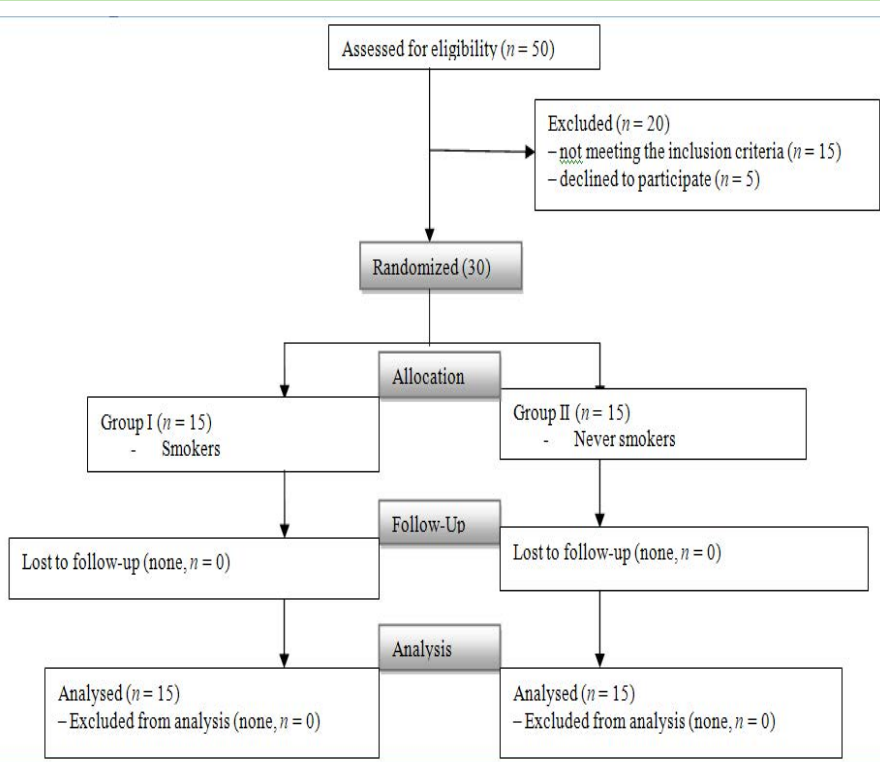

Figure 1: Consort diagram. Smokers Group I, Never-smokers Group II.

Predominant clinical diagnosis in I and II group was kidney cancer (26.6\%). Interventions were 30\% laparoscopic and $70 \%$ open surgeries. In table 1 are presented the baseline demographics and clinical characteristics of patients and the attributes of the surgery.

Table 1: Patient and surgical baseline characteristics within each group $($ Mean $\pm \mathrm{SD})$.

\begin{tabular}{|l|l|l|}
\hline Variable & $\begin{array}{l}\text { Group Smokers } \\
\mathbf{n = 1 5}\end{array}$ & $\begin{array}{l}\text { Group Non- } \\
\text { smokers n = 15 }\end{array}$ \\
\hline Sex M/F & $11 / 4$ & $10 / 5$ \\
\hline Age & $50.2 \pm 12.84$ & $49.93 \pm 13.99$ \\
\hline ASA I/II & $0 / 15$ & $2 / 13$ \\
\hline BMI (m2) & $25.84 \pm 3.5$ & $25.92 \pm 2.76$ \\
\hline Surgery Open/Laparoscopic & $11 / 4$ & $11 / 4$ \\
\hline Anesthesia time (min) & $143.3 \pm 62.38$ & $159.33 \pm 64.65$ \\
\hline Operation time (min) & $174.66 \pm 68.2$ & $196.6 \pm 67.65$ \\
\hline Blood transfusion (no/yes) & $10 / 5$ & $7 / 8$ \\
\hline Transfusion unit & 1 & 1.4 \\
\hline Operation & & \\
\hline Nephrectomy & 7 & 6 \\
\hline Varicocele repair & 2 & 2 \\
\hline Radical prostatectomy & 3 & 4 \\
\hline Radical cystectomy & 3 & 3 \\
\hline
\end{tabular}

Abbreviations: F - female; M - male; ASA- American Society of Anesthesiologist, BMI-Body Mass Index; NS-Not significant $(p>0.05)$
Table 2: Hemodynamic data of the patients (Mean $\pm \mathrm{SD}$ ).

\begin{tabular}{|c|c|c|}
\hline Variable & Group Smokers n=15 & Group Non-smokers n=15 \\
\hline$H R-T_{0}$ & $82.26 \pm 12.62$ & $81.73 \pm 8.09$ \\
\hline $\mathrm{HR}-\mathrm{T}_{1}$ & $71.93 \pm 12.04$ & $64.26 \pm 7.55$ \\
\hline $\mathbf{H R}-\mathrm{T}_{2}$ & $74.13 \pm 11.75$ & $74.13 \pm 11.75$ \\
\hline SBP - $T_{0}$ & $147.2 \pm 20.53$ & $152.133 \pm 19.6$ \\
\hline $\mathrm{SBP}-\mathrm{T}_{1}$ & $120 \pm 13.2$ & $114.73 \pm 8.36$ \\
\hline $\mathrm{SBP}-\mathrm{T}_{2}$ & $123.66 \pm 19.88$ & $123.4 \pm 8.95$ \\
\hline DBP - $T_{0}$ & $85.4 \pm 18.57$ & $84.66 \pm 10.01$ \\
\hline DBP - $T_{1}$ & $67.26 \pm 7.44$ & $70.4 \pm 9.98$ \\
\hline DBP - $T_{2}$ & $72.6 \pm 6.73$ & $75.2 \pm 8.1$ \\
\hline \multicolumn{3}{|l|}{ Fluids Infusion } \\
\hline$\leq 6\left(\mathrm{ml} \mathrm{kg}^{-1} \mathrm{~h}^{-1}\right)$ & $\mathrm{n}=1$ & $\mathrm{n}=1$ \\
\hline 6 to $9\left(\mathrm{ml} \mathrm{kg}^{-1} \mathrm{~h}^{-1}\right)$ & $\mathrm{n}=1$ & $\mathrm{n}=2$ \\
\hline 9 to $13\left(\mathrm{ml} \mathrm{kg}^{-1} \mathrm{~h}^{-1}\right)$ & $\mathrm{n}=13$ & $\mathrm{n}=12$ \\
\hline
\end{tabular}

Data are expressed as mean \pm standard error of the mean.

$\mathrm{T}_{0}$ - preoperative; $\mathrm{T}_{1}$ - after preoxygenation; $\mathrm{T}_{2}$ - one hour after induction in anesthesia; HR - heart rate; $\mathrm{BP}$ - blood pressure

Table 2 present the hemodynamic data of the patients. Fluid therapy for the first perioperative hour was similar in groups, $(1120 \pm 211.11$ vs. $1100 \pm 207.01)$ for the smoking group and for the non-smoking group.

Table 3: Perioperative changes in carboxyhemoglobin and methemoglobin in the Smoking and Non-smoking Group.

\begin{tabular}{|c|c|c|c|}
\hline & $T_{0}$ & $T_{1}$ & $\mathbf{T}_{2}$ \\
\hline \multicolumn{4}{|c|}{ Group Smokers $n=15$} \\
\hline СОНb \% & $2.1 \pm 1.02$ & $1.92 \pm 0.97$ & $1.88 \pm 0.63$ \\
\hline MetHb \% & $0.18 \pm 0.11$ & $0.27 \pm 0.14$ & $0.3 \pm 0.11$ \\
\hline Total Hb g/L & $137.73 \pm 24.3$ & $121.13 \pm 30.18$ & $115.4 \pm 18.76$ \\
\hline $\mathrm{FO}_{2} \mathrm{Hb} \%$ & $93.7 \pm 2.46$ & $96.17 \pm 2.34$ & $92.5 \pm 2.42$ \\
\hline $\mathrm{PCO}_{2} \mathrm{mmHg}$ & $38.07 \pm 6.16$ & $45.62 \pm 10.31$ & $44.54 \pm 7.91$ \\
\hline $\mathrm{PO}_{2} \mathrm{mmHg}$ & $78.96 \pm 10.81$ & $166.67 \pm 128.2$ & $85.12 \pm 19.57$ \\
\hline \multicolumn{4}{|c|}{ Group Non-smokers $n=15$} \\
\hline COHb \% & $0.47 \pm 0.27$ & $0.42 \pm 0.34$ & $0.4 \pm 0.18$ \\
\hline MetHb \% & $0.3 \pm 0.16$ & $0.38 \pm 0.21$ & $0.29 \pm 0.12$ \\
\hline Total Hb g/L & $139.46 \pm 22.9$ & $131.2 \pm 22.54$ & $114.26 \pm 18.22$ \\
\hline $\mathrm{FO}_{2} \mathrm{Hb} \%$ & $96.52 \pm 1.66$ & $98.08 \pm 0.78$ & $95.35 \pm 2.37$ \\
\hline $\mathrm{PCO}_{2} \mathrm{mmHg}$ & $38.61 \pm 5.07$ & $39.3 \pm 8.62$ & $40.11 \pm 6.35$ \\
\hline $\mathrm{PO}_{2} \mathrm{mmHg}$ & $83.94 \pm 8.95$ & $157.25 \pm 56.85$ & $93.21 \pm 12.78$ \\
\hline
\end{tabular}

Data are expressed as mean \pm standard error of the mean.

$\mathrm{T}_{0}$ - preoperative; $\mathrm{T}_{1}$ - after preoxygenation; $\mathrm{T}_{2}$ - one hour after surgery; $\mathrm{COHb}$ - carboxyhemoglobin; Hb - hemoglobin; MetHb - methemoglobin;

$\mathrm{FO}_{2} \mathrm{Hb}$ - fractional oxyhemoglobin; $\mathrm{PCO}_{2}$ - partial pressure of carbon dioxide; $\mathrm{PO}_{2}$ - partial pressure of oxygen.

Table 3 shows the effect of smoking on the perioperative changes in $\mathrm{COHb}$, MetHb, total $\mathrm{HB}, \mathrm{PCO}_{2}, \mathrm{PO}_{2}$, and $\mathrm{FO}_{2} \mathrm{Hb}$. Compered between groups $\mathrm{COHb}$ was significantly higher at all three time points in group I smokers. In the second time point $\mathrm{T}_{1}$ after preoxygenation $\mathrm{COHb}$ was decreased and in the third time 
Citation: Gavrilovska-Brzanov, A., et al. Carboxyhemoglobin and Methemoglobin as Markers of Postoperative Pulmonary Complications. (2018) J Anesth Surg 5(1): $61-67$.

point $\mathrm{T}_{2}$ one hour after surgery, $\mathrm{COHb}$ was as well decreased due to mechanical ventilation. In both groups, MetHb increased in $\mathrm{T}_{1}$ after preoxygenation. In $\mathrm{T}_{2}$ there were differences regarding $\mathrm{MetHb}$ in both groups, in group II never smokers the level of MethHb was lower than preoperative baseline level, but without significant difference $(\mathrm{p}>0.05)$ and significantly increased in the group I smokers $(\mathrm{p}<0.05)$.

Table 4: Postoperative pulmonary complications in the Smoking and Non-smoking Group.

\begin{tabular}{|l|c|c|}
\hline Variable & $\begin{array}{l}\text { Group Smokers } \\
\mathbf{n = 1 5}\end{array}$ & $\begin{array}{l}\text { Group Non-smok- } \\
\text { ers n = 15 }\end{array}$ \\
\hline Postoperative pulmonary complications \\
\hline Total PPC & 4 & 2 \\
\hline Prolonged intubation & 1 & 1 \\
\hline Atelectasis & 1 & 1 \\
\hline Pneumonia & 1 & 0 \\
\hline ARI & 1 & 0 \\
\hline Postoperative outcome & & \\
\hline Lenth of hospital stay & $6.21 \pm 3.7$ & $4.73 \pm 2.6$ \\
\hline Post Op. ICU admission & 1 & 0 \\
\hline In hospital mortality & 0 & 0 \\
\hline
\end{tabular}

Abbreviations: PPC - postoperative pulmonary complications, ARI acute respiratory insufficiency.

The level of $\mathrm{COHb}$ in groups smokers and never smokers decreased postoperatively $(2.1 \pm 1.02$ vs. $1.88 \pm 0.63)$ vs. $(0.47 \pm 0.27$ vs. $0.4 \pm 0.18)$. The average values of $\mathrm{COHb}$ between the groups were statistically significantly different. At baseline preoperative value $\mathrm{T}_{0}$ was $\mathrm{p}=0.000$, at the second time point $T_{1}$ after preoxygenation the $\mathrm{p}$ value was 0.000 and at the postoperative time point $\mathrm{T}_{2}, \mathrm{p}=0.000$. MetHb level on the other hand increased postoperatively (from $0.18 \pm 0.11$ vs. $0.3 \pm$ 0.11 ) in group I smokers and decreased (from $0.3 \pm 0.16$ vs. 0.29 \pm 0.12 ) in group II never-smokers. The average postoperative values of $\mathrm{MetHb}$ were as follows: at baseline preoperative time point $\mathrm{T}_{0}, \mathrm{p}=0.02$, at the second time point after preoxygenation $\mathrm{T}_{1}, \mathrm{p}=0.10$ and at the last postoperative time point $\mathrm{T}_{2}, \mathrm{p}=0.88$. (Graph 1).

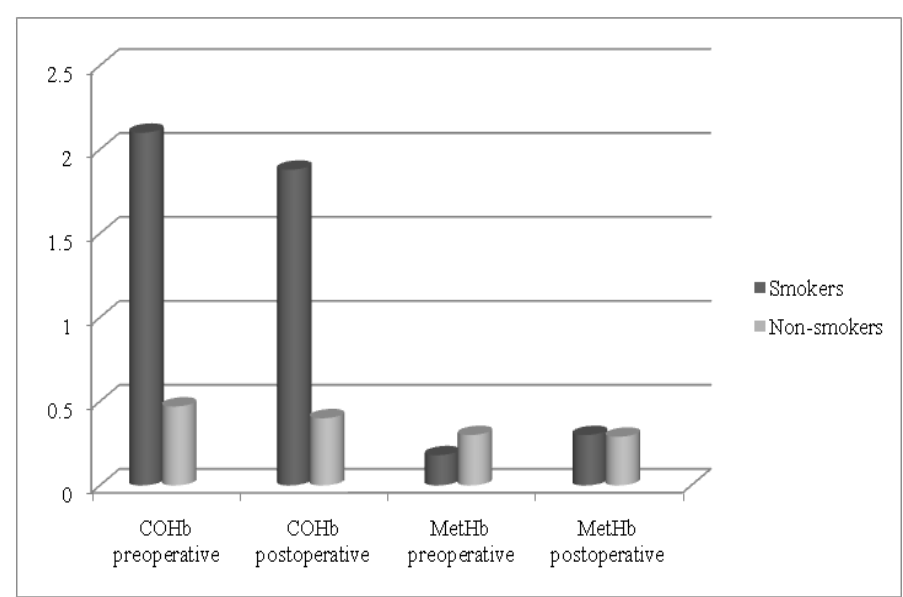

Graph 1: Change of the average values of $\mathrm{CoHb}$ and MetHb in the groups.
Regarding postoperative pulmonary complications, $13.3 \%$ of the patients in the control non-smokers group and $26.6 \%$ of the patients in smokers group had pulmonary complications. In the smokers group one patient had pneumonia, other patient had atelectasis and one patient required ICU admission due to respiratory insufficiency. On the other hand patients in never smoking group didn't required ICU admission, one patient had prolonged intubation due to spasm and other patient was with atelectasis. The most frequent PPC are shown in Table 4 together with the second outcome measures. (Table 4)

We found statistical significance between the BMI and PRK (Pearson Chi-square: 4.80159, $\mathrm{p}=.028434$ ). We found statistically significant moderate positive correlation between the time of surgery and PRK (Spearman Rank Order Correlations $\mathrm{R}=-0,448197)$

\section{Discussion}

This prospective clinical study evaluates and tests the prognostic value of the level of $\mathrm{COHb}$ and $\mathrm{MetHb}$ in elective urologic patients who have undergone general endotracheal anesthesia. The analysis has clearly indicated that smoking increases exogenous $\mathrm{COHb}$. On the other hand, the MetHb is increased in control non-smokers group. The study of Chin-Sheng confirmed that the influence of smoking is the most impotent determinant for the production of $\mathrm{CO}$ and $\mathrm{COHb}$, not the type of anesthesia and/or the degradation products from anesthetics ${ }^{[17]}$.

By the literature review of Dries, on room air the halflife of carboxyhemoglobin is 250 minutes. This is reduced to 40 to 60 minutes with inhalation of $100 \%$ oxygen $^{[18]}$. In our study the influence of preoxygenation with $100 \%$ oxygen on the level of $\mathrm{COHb}$ and MetHb resulted in decreased $\mathrm{COHb}$ in both groups, and significantly increased MetHb. These findings correlate with those of Adachi et al. showing that general endotracheal anesthesia with inhaled fraction of oxygen higher than $35 \%$ decreased the level of $\mathrm{COHb}$ and increased the level of MetHb compared to basal values. At the same time, general endotracheal anesthesia with inhaled fraction of oxygen lower than $35 \%$ had no influence on $\mathrm{COHb}$ and $\mathrm{MetHb}^{[19]}$. Many studies suggest determination of $\mathrm{COHb}$ in clinical practice ${ }^{[20]}$. The risk of anesthesia and the incidence of postoperative respiratory complications are increased in smoking population ${ }^{[21]}$. It has been reported that $\mathrm{COHb}$ is produced by the interaction of volatile anesthetics, including sevo $\neg$ flurane ${ }^{[22]}$. We eliminated the influence of $\mathrm{COHb}$ production through this interaction in our study, as we used intravenous anesthesia. Levy et al. ${ }^{[23]}$ in their study observed a significant increase of $\mathrm{COHb}$ during general anesthesia in infants and children when low flow anesthesia was used. In our study normal flow anesthesia was used in all patients. Contrary to the study of Takeda, were nitrous oxide $\left(\mathrm{N}_{2} \mathrm{O}\right)$ had been used in all cases $^{[24]}$, contamination of $\mathrm{NO}$ in $\mathrm{N}_{2} \mathrm{O}$ gas was completely negligible. In our study $\mathrm{N}_{2} \mathrm{O}$ was not used, therefore the increase of MetHb postoperatively was ascribed to endogenous $\mathrm{NO}$ or some other autoxidizing mechanism which converts ferrous heme $\left(\mathrm{Fe}^{+2}\right)$ to ferric heme $\left(\mathrm{Fe}^{+3}\right)$. Increase of $\mathrm{MetHb}$ postoperatively after blood transfusion can be assigned to autoxidation of heme of the preserved red cell in the recipient. Increased levels of $\mathrm{COHb}$ correlate with an increased ICU mortality in critically ill medical patients, hence $\mathrm{COHb}$ can serve 
as a predictive marker for ICU severity of illness ${ }^{[25,26]}$. This has also been confirmed by Togores et al. ${ }^{[27]}$, who found that the correlation between $\mathrm{CO}$ and $\mathrm{COHb}$ depended on the level of obstruction in the airways. In our study, despite the fact that the enrolled patients were smokers, they were ASA I and II and we believe that the obstruction of the airway is negligible. Kakavas et al. in their study investigated the prognostic value of arterial $\mathrm{COHb}$ and $\mathrm{MetHb}$ in patients with acute pulmonary embolism. Their preliminary data suggest that arterial $\mathrm{COHb}$ and $\mathrm{MetHb}$ levels reflect the severity of acute pulmonary embolism. In univariate logistic regression analysis, $\mathrm{COHb}$ and $\mathrm{MetHb}$ levels, both significantly correlated with increased Acute Physiology and Chronic Health Evaluation II score and decreased $\mathrm{PaO}_{2} / \mathrm{FiO}_{2}$ ratio. However, in multivariate analysis, only $\mathrm{COHb}$ remained significant as an independent predictor of in-hospital mortality and the increased level of MetHb is associated with severe illness, but these findings require further prospective validation ${ }^{[28]}$.

The study of Naples ${ }^{[29]}$ identified an increase of arterial $\mathrm{COHb}$ levels in stable asthma, suggesting that asthmatics produce more $\mathrm{CO}$ in the lung and offload more $\mathrm{CO}$ to tissues than healthy controls. Furthermore, the finding of a lower than normal MetHb level in asthmatics was unexpected. A higher than normal MetHb level was anticipated in asthma on the basis that $\mathrm{NO}$ can oxidize the $\mathrm{Fe}^{+2}$ in heme to $\mathrm{Fe}^{+3}$ to produce $\mathrm{Me}$ $\mathrm{tHb}^{[30]}$. In the present study the investigated group of smokers with significantly increased level of $\mathrm{COHb}$ and no significantly increased level of MetHb had higher incidence rate of PPC. The multicenter observational study LAS VEGAS ${ }^{[31]}$ shows that PPC occur frequently in patients at increased risk, with worse clinical outcome. In their study the most frequently chosen $\mathrm{V}_{\mathrm{T}}$ was 500 $\mathrm{ml}$, which corresponds to $\mathrm{V}_{\mathrm{T}}$ between 7 and $9 \mathrm{ml} \mathrm{kg}^{-1}$ predicted body weight, and the most frequently chosen PEEP levels were 0 to $5 \mathrm{~cm} \mathrm{H}_{2} \mathrm{O}$. PEEP levels more than $5 \mathrm{~cm} \mathrm{H}_{2} \mathrm{O}$ was used in minority of patients. They concluded that a large proportion of patients receive high $\mathrm{V}_{\mathrm{T}}$ and low PEEP levels, seemingly independent of the risk of PPC. In our study we chose the mechan-

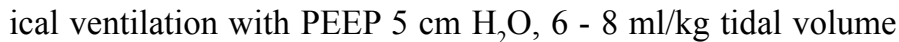
$\left(\mathrm{V}_{\mathrm{T}}\right)$ for healthy individuals ASA I and II with no history of any respiratory disease. Elimination of locally generated $\mathrm{CO}$ occurs through its displacement from $\mathrm{Hb}$ and its later excretion from the lungs as a gas without undergoing changes. The alveolar partial pressure of oxygen determines the exchange rate between $\mathrm{CO}$ and oxygen. These are the reasons that can alter the concentration of $\mathrm{COHb}$ in the arterial blood samples: surgical trauma, hemoglobin concentration, tissue oxygenation and pulmonary function $^{[32]}$. Due to the above-mentioned, in our study we excluded all patients with lung disease or systemic inflammation, and we fixed the inspired oxygen fraction to 0.5 except for the time of preoxygenation when we used $100 \%$ oxygen for 3 minutes. During the whole perioperative period we were trying to maintain the $\mathrm{Hb}$ level in normal ranges. In spite of the strict selection of patients and the perioperative management, the values of $\mathrm{COHb}$ and MetHb were not constant.

Studies in specific surgical populations or large patient samples have identified a range of predictors of PPC risk. On one hand, factors such as age, types of comorbidity, body mass index (BMI) and smoking status have been found to be relevant in most of these studies. On the other hand PRK depend of the type of surgery, incision, type of anesthesia, total time of surgery ${ }^{[1,11,33,34]}$. In our study we include and analyzed all of the above mentioned parameters. We included only ASA I and II patients (normal patients and patients with mild systemic disease). Elderly patients are at increased risk for developing $\mathrm{PRK}^{[1,33]}$, in our study we include only patients till 65 years. We found statistical significance between the BMI and PRK. As for smoking status we found higher incidence of PRK in smoking group. We had patients undergoing open and laparoscopic surgeries. Laparoscopic interventions are not invasive, safety for the patients, insure better analgesia. In our study one patient of smoking group with laparoscopic intervention had atelectasis and one patient in no-smoking group with laparoscopic intervention developed atelectasis. All the others complications were in open surgeries. We found statistically significant moderate positive correlation between the time of surgery and PRK. The presented data in literature suggest using regional anesthesia whenever possible due to lower rate of PRK, in our study we included only patients under general endotracheal anesthesia.

The analysis indicated that smoking increases $\mathrm{COHb}$ and that the effect of smoking remains even after mechanical ventilation. We have also shown that preoxygenation with $100 \%$ oxygen decreased the blood $\mathrm{COHb}$ concentration and increased $\mathrm{MetHb}$, but not significantly. In our sample there was a difference between the incidence rates of PPC; however we cannot confirm the hypothesis that $\mathrm{COHb}$ and $\mathrm{MetHb}$ can serve as predictors for PPC.

Further investigations are needed to assess possibility of predictions of pulmonary complications by level of carboxyhemoglobin and methemoglobin.

For interpretation of the above-mentioned results we have to take into consideration the limitation of our study. A major limitation of this study is the relatively small sample size in both subgroups that makes statistical analysis difficult. The study was open for investigators. By the literature most frequent interventions with increased risk for developing PRK are vascular, thoracic and upper abdominal interventions. This study analyzed only urologic interventions. The preliminary observations of our study require further validation in larger prospective populations in order to clarify the underlying mechanisms of $\mathrm{COHb}$ and MetHb as prognostic markers for PPC.

Acknowledgements: Financial support and sponsorship: none. Conflicts of interest: none. 
Citation: Gavrilovska-Brzanov, A., et al. Carboxyhemoglobin and Methemoglobin as Markers of Postoperative Pulmonary Complications. (2018) J Anesth Surg 5(1): $61-67$.

\section{References}

1. Haller, G., Walder, B. Postoperative pulmonary complications - still room for improvement. (2017) Eur J Anaesthesiol 34(8): 489-491.

PubMed | Crossref $\mid$ Others

2. Canet, J., Hardman, J., Sabaté, S., et al. PERISCOPE study: predicting post-operative pulmonary complications in Europe. (2011) Eur J Anaesthesiol 28(6): 459-461.

PubMed | Crossref | Others

3. Staehr-Rye, A.K., Eikerma, M. Eliminate postoperative respiratory complications: preoparative screening opens the door to clinical pathway that individualise perioperative treatment. (2015) Eur J Anaesthesiol 32(7): 455-457.

PubMed $\mid$ Crossref $\mid$ Others

4. Krueger, J.K., Rohrich, R.J. Clearing the smoke: the scientific rationale for tobaccoabstention with plastic surgery. (2001) Plast Reconst Surg 108(4): 1063-1073.

PubMed | Crossref | Others

5. Pearce, A.C., Jones, R.M. Smoking and Anaesthesia: pre-operative abstinence and perioperative morbidity. (1984) Anaesthesiology 61(5): 576-584.

PubMed $\mid$ Crossref $\mid$ Others

6. Woehlck, H.J., Connolly, L.A., Cinquegrani, M.P., et al. Acute smoking increases STdepression in humans during general anaesthesia. (1999) Anaesth Analg 89(4): 856-860. PubMed $\mid$ Crossref $\mid$ Others

7. Cox, B.D., Whichelow, M. Carbon monoxide levels in the breath of smokers and non-smokers: effect of domestic heating system. (1985) J Epidemiol Community Health 39(1): 75-78.

\section{PubMed | Crossref $\mid$ Others}

8. Institute for Environment and Health: IEH assessment on indoor air quality in the home(2): carbon monoxide. (1998) In Report, Institute for Environment and Health Leicester, UK.

\section{PubMed $\mid$ Crossref $\mid$ Others}

9. Haymond, S., Cariappa, R., Eby, C.S., et al. Laboratory assessment of oxygenation in methemoglobinemia. (2004) Clin Chem 51(2): 434-444.

PubMed | Crossref $\mid$ Others

10. Whincup, P., Papacosta, O., Lennon, L., et al. Carboxyhaemoglobin levels and their determinants in older British men. (2006) BMC Public Health 6: 189-197.

PubMed | Crossref | Others

11. Canet, J., Sabaté, S., Mazo, V., et al. Development and validitationos a score to predict postoperative respiratory failure in a multicentric European cohort. A prospective, observational study. (2015) Eur J Anaesthesiol 32(7): 458-470.

PubMed | Crossref | Others
12. Sakamoto, A., Nakanishi, K., Takeda, S., et al. Does Carboxy-hemoglobin Serve as a Stress-induced Inflammatory Marker Reflecting Surgical Insults? (2005) J Nippon Med Sch 72(1): 19-28.

PubMed | Crossref | Others

13. Cotes, J.E. Research Council Questionnaire on Respiratory Symptoms (1986). (1987) Lancet 2(8566): 1028.

PubMed | Crossref | Others

14. Kohonen, M., Teerenhovi, O., Terho, T., et al. Is the Allen test reliable enough? (2007) Eur J Cardiothorac Surg 32(6): 902-905.

PubMed | Crossref | Others

15. Jammer, I., Wickboldt, N., Sander, M., et al. Standards for definitions and use of outcome measures for clinical effectiveness research in perioperative medicine: European Perioperative Clinical Outcome (EPCO) definitions. (2015) Eur J Anaesthesiol 32(2): 88-105.

PubMed | Crossref | Others

16. Brooks-Brunn, J.A. Predictors of postoperative pulmonary complications following abdominal surgery. (1997) Chest 111(3): 564-571.

PubMed | Crossref $\mid$ Others

17. Chin-Sheng, T., Shou-Zen, F., Chang-Chuan, C. Smoking status and body size increase carbon monoxide concentrations in the breathing circuit during low-flow anesthesia. (2001) Anesth Analg 92(2): 542-547.

PubMed | Crossref $\mid$ Others

18. Dries, D., Frederick, E. Inhalation injury: epidemiology, pathology, treatment strategies. (2013) Scand J Trauma Resusc Emerg Med 21: 31.

PubMed | Crossref $\mid$ Others

19. Adachi, T., Hirota, K., Hara, T., et al. Exhaled carbon monoxide levels change in relation to inspared oxygen fraction during general anesthesia. (2007) Anesth Analg 105(3): 696-699.

PubMed | Crossref | Others

20. Andersson, M.F., Moller, M.A. Assessment of carbon monoxide values in smokers: a comparison of carbon monoxide in expired air and carboxyhaemoglobin in arterial blood. (2010) Eur J Anaesthesiol 27(9): 812-818.

PubMed | Crossref | Others

21. Warner, D.O. Tobacco control for anesthesiologists. (2007) J Anesth 21(2): 200-211.

PubMed | Crossref | Others

22. Janshon, G.P., Dudziak, R. Interactions of dry soda lime with enflurane and sevcoflurane. Clinical report on two unusual anesthesias. (1997) Der Anesthetsist 46(12): 1050-1053.

PubMed | Crossref | Others 
23. Levy, R., Nasr, V., Rivera, O., et al. Detection of carbon monoxide during routine anesthetics in infants and children. (2010) Anesth Analg 110(3): 747-753.

\section{PubMed | Crossref | Others}

24. Takeda, Y., Tanaka, A., Maeda, T., et al. Perioperative changes in carbonylhemoglobin and methemoglobin during abdominal surgery: Alteration in endogenous generation of carbon monoxide. (2002) J Gastroenterol Hepatol 17(5): 535-541.

PubMed | Crossref | Others

25. Morimatsu, H., Takahashi, T., Maeshima, K., et al. Increased hemecatabolism in critically ill patients: correlation among exhaled carbon monoxide, arterial carboxyhemoglobin, and serum bilirubin IX alpha concentrations. (2006) Am J Physiol Lung Cell Mol Physiol 290(1): L114-L119. PubMed | Crossref | Others

26. Hayashi, M., Takahashi, T., Morimatsu, H., et al. Increased carbon monoxide concentration in exhaled air after surgery and anesthesia. (2004) Anesth Analg 99(2): 444-448.

PubMed | Crossref $\mid$ Others

27. Togores, B., Bosch, M., Agusti, A.G. The measurement of exhaled carbonmonoxide is influenced by airflow obstruction. (2000) Eur Respir J 15(1): 177-180.

PubMed | Crossref | Others

28. Kakavas, S., Papanikolaou, A., Ballis, E., et al. Carboxyhemoglobin and methemoglobin levels as prognostic markers in acute pulmonary embolism. (2015) Am J Emerg Med 33(4): 563-568.

PubMed | Crossref | Others
29. Naples, R., Laskowski, D., McCarthy, K., et al. Carboxyhemoglobin and Methemoglobin in Asthma. (2015) Lung 193(2): 183-187.

PubMed | Crossref | Others

30. Soro, M., García-Pérez, M.L., Ferrandis, R., et al. Closed-systemanaesthesia for laparoscopic surgery: is there a risk for carbon monoxide intoxication? (2004) Eur J Anaesthesiol 21(6): 483-488.

PubMed | Crossref | Others

31. Schultz, J.M. Epidemiology, practice of ventilation and outcome for patients at increased risk of postoperative pulmonary complications: LAS VEGAS - an observational study in 29 countries. (2017) Eur J Anaesthesiol 34(8): 492-507.

PubMed | Crossref $\mid$ Others

32. Zegdi, R., Caïd, R., Van De Louw, A., et al. Excaled carbon monoxide in mechanically ventilated critically ill patients: influence of inspared oxygen fraction. (2000) Intensive Care Med 26(9): 1228-1231.

PubMed | Crossref $\mid$ Others

33. Arozullah, A.M., Khuri, S.F., Henderson, W.G., et al. Development and validation of a multifactorial risk index for predicting postoperative pneumonia after major non cardiac surgery. (2001) Ann Intern Med 135(10): 847-857.

PubMed | Crossref | Others

34. Rudra, A., Sudipta, D. Postoperative pulmonary complications. (2006) Ind J Anaesth 50(2): 89-98.

PubMed $\mid$ Crossref $\mid$ Others
Submit your manuscript to Ommega Publishers and we will help you at every step:

- We accept pre-submission inquiries

- Our selector tool helps you to find the most relevant journal

- We provide round the clock customer support

- Convenient online submission

- Thorough peer review

- Inclusion in all major indexing services

- Maximum visibility for your research

Submit your manuscript at

https://www.ommegaonline.org/submit-manuscript 